\title{
Experiência: o planejamento ascendente e participativo para construção da programação anual 2008 em Várzea Paulista
}

Luís Fernando Nogueira Tofani, Maria do Carmo Cabral Carpintéro

Prefeitura Municipal de Várzea Paulista. Secretaria Municipal de Saúde.

Endereço: Rua Célio Barbosa, 65, Vila Santa Terezinha, CEP 12220-10o, Várzea Paulista, SP, Brasil.

E-mail: luis.tofani@gmail.com

Desde 2005 têm sido utilizadas técnicas de planejamento para construção do Plano Municipal de Saúde, dos Relatórios de Gestão e Programações Anuais em Várzea Paulista. A estruturação de um processo ascendente e participativo, incluindo trabalhadores, gestores e usuários de todos os serviços em 2007 para formulação da Programação Anual 2008, contemplou: formação em Planejamento Estratégico; autoavaliação das equipes; elaboração dos planos locais; definição das prioridades, ações e indicadores para 2008, organizadas nos cinco blocos do Pacto pela Saúde; consolidação e aprovação pelo Conselho Municipal de Saúde. Essa construção por meio de um debate participativo e ascendente tem facilitado o envolvimento de todos os segmentos na execução, além de permitir a pactuação de um plano real e factível, desencadeando a reorganização do processo de trabalho e de gestão na Secretaria Municipal de Saúde. 